\title{
Pensamento projetual, natureza e artifício: algumas considerações epistemológicas ${ }^{1}$
}

\author{
Design thinking, nature and artifice: a few epistemological considerations
}

\author{
PORTUGAL, Daniel B.; Doutor; ESDI/UERJ \\ dportugal@esdi.uerj.br \\ HAGGE, Wandyr; Doutor; ESDI/UERJ \\ wandyr@gmail.com
}

\section{Resumo}

Com o objetivo de refletir sobre as características do pensamento projetual, ou design thinking, este artigo se debruça sobre diversas questões epitemológicas, começando por acompanhar a crítica de Hume à indução. Em seguida, são realizadas considerações sobre a noção Peirceana de abdução, sobre a lógica das descobertas e das provas no pensamento científico e sobre a pressuposição da existência de uma natureza uniforme, com "leis" universais e imutáveis. Tendo como principal base as propostas de Bruno Latour, observamos que a oposição entre natureza e artifício não se sustenta. Em vez dessa oposição, situamos, de um lado, uma forma dogmática de colocar questões - na qual estas aparecem já norteadas -, e, de outro, uma forma relativista de lidar com os problemas, na qual não há norte estabelecido de antemão. Tais são os problemas desnorteadores - ou wicked problems - com os quais o pensamento projetual precisa lidar.

Palavras Chave: pensamento projetual; natureza e artifício; abdução.

\begin{abstract}
In order to reflect on the characteristics of design thinking, this article approaches several epistemological problems, beginning with Hume's critique of the role of induction in the production of knowledge. This is followed by some considerations about the notion of abduction, about the logic of discoveries and of evidence in scientific thought, and about the notion of a nature assumed to be uniform, with universal and immutable "laws". Based mainly on the ideas of Bruno Latour, we observe that the opposition between nature and artifice does not hold upon close scrutinity. As an alternative to this opposition, we separate a dogmatic way of placing questions-in which they appear already oriented-from a relativistic way of dealing with problems, in which there is no preestablished north. Such are the bewildering problems-or wicked problems-that design thinking has to deal with.
\end{abstract}

Keywords: design thinking ; nature and artifice ; abduction.

\footnotetext{
${ }^{1}$ Este artigo derivou-se de debates no Grupo de Estudo sobre Design, Epistemologia e Moralidade (DEMO), da ESDI/UERJ, coordenado pelos autores. Pela rica troca de ideia, agradecemos aos demais integrantes do grupo: João Sarmento, Andrea Marroquim, Laura Gadelha, Silvia Davis e Julio Nogueira.
} 


\section{Design thinking: ou pensamento projetual}

A definição de design, como se sabe, é objeto de constantes disputas. Antigamente, as discussões costumavam girar em torno do objeto do design: forma ou função? Artefato ou sistema? Informação ou persuasão? Só o "planejamento" ou também as "especificidades do fazer"? Só objetos industriais ou qualquer objeto? Atualmente, embora as controvérsias acerca da definição de design continuem acirradas, boa parte do debate se deslocou da questão do objeto para a do processo do design. Que tipo de atividade é o projetar? O que está nela envolvido? Que tipo de pensamento organiza tal atividade?

A última pergunta foi a que ganhou mais notoriedade e, com ela, um apanhado de novos termos, dentre eles o hoje onipresente design thinking. Esse conceito procura - quando não utilizado de maneira "solta" - indicar um modo de pensar específico dessa atividade chamada design. Isso, claro, não resolve a questão de saber o que, exatamente, caracteriza tal modo de pensar. A disputa continua. Mas, se o design se define por um modo de pensamento, a questão de saber a que objetos ele se aplica torna-se secundária. Por isso, muitos daqueles que abordaram o design a partir do ponto de vista do processo de pensamento a ele relacionado ligaram-no a outras atividades, algumas vezes bem distantes das definições do design mais preocupadas com seu objeto. Herbert Simon, por exemplo, escreve em The sciences of the artificial: "a atividade intelectual que produz artefatos materiais não é fundamentalmente diferente daquela que prescreve remédios para um paciente doente ou daquela que divisa um novo plano de vendas para uma empresa, ou uma política de bem-estar social para um governo" (SIMON, 1996, p. 111; tradução nossa). ${ }^{2}$

Quando começamos a refletir sobre o que todas essas atividades intelectuais possuem em comum, e como elas partem de um problema para chegar a uma solução, inevitavelmente levantaremos questões epistemológicas que remontam pelo menos ao século XVIII. O foco do debate de então eram as ciências naturais - ou "filosofia natural", como eram chamadas à época. E hoje, a reflexão sobre as "ciências do artificial" tende a remeter às "ciências naturais", seja para diferenciar uma da outra, como faz Simon, seja para mostrar, como Bruno Latour (2015), que a dicotomia não se sustenta - porque a natureza é artificial e o artifício, natural.

\section{A ciência e o problema da indução}

No século XVIII, um dos marcos do debate epistemológico foi a crítica de Hume (2008) à indução. Esta, como se sabe, é um tipo de inferência que vai do particular ao universal e diz respeito, como coloca Hume, aos fatos. Por exemplo: ao perceber o sol nascer todos os dias, concluímos indutivamente que ele nascerá amanhã, ou que ele continuará a nascer todos os dias.

\footnotetext{
${ }^{2}$ A obra em questão foi publicada pela primeira vez em 1969, ou seja, há quase meio século. Apesar disso, queremos crer que não abusamos da elasticidade de termos como "atualmente" e "antigamente" quando afirmamos, no primeiro parágrafo, que "antigamente" as abordagens do design estavam mais focadas no objeto e "atualmente" centram-se, mais comumente, na questão no pensamento projetual. Herbert Simon - como Bruce Archer e Horst Rittel - pode ser visto como precursor das abordagens do design centradas no pensamento projetual, que só começarão a se consolidar e ganhar notoriedade nas décadas de 1980 e 1990. Mas deixamos em aberto a questão de saber se o termo "atualmente" é elástico o suficiente para cobrir um período de 30 anos.
} 
A dedução, por sua vez, segue do universal ao particular, na forma do silogismo aristotélico, e diz respeito à concatenação de ideias. Por exemplo: se toda estrela emite luz, e o sol é uma estrela, deduzimos que o sol emite luz. Como está claro, para realizar uma dedução, não preciso ter nenhuma experiência empírica - no caso com o sol -, pois seria simplesmente contraditório que o sol não emitisse luz se toda estrela emite luz e o sol é uma estrela. No caso da indução, o mesmo não ocorre: não há nenhuma contradição lógica se o sol parar de nascer, assim como acordamos vivos todos os dias de nossa vida - até que um dia isso não acontece mais.

Como nota Hume, as induções que nos levam a criar leis da natureza só ganham base lógica por recorrerem tacitamente à premissa de que a natureza é uniforme. Nesse caso, poderíamos construir uma espécie de silogismo da seguinte forma: o que acontece hoje acontecerá sempre; o sol nasceu hoje; logo, o sol nascerá amanhã e em todos os demais dias. Contudo, como é possível ter certeza acerca da uniformidade da natureza? Temos apenas a experiência empírica da uniformidade no passado, e só poderíamos inferir indutivamente que a natureza será uniforme no futuro. Mas não há nenhuma base lógica para fazê-lo - aqui, não há nenhuma premissa tácita que pudesse justificar a conclusão.

Embora Hume não siga esse caminho, seu argumento sugere que a noção de uniformidade encontra-se enraizada como autoevidente na própria noção de natureza. Como percebe Bruno Latour (2015), a "natureza" que normalmente está em jogo nas ciências naturais é um campo do qual foi excluída toda possibilidade de desvio, variação, agência. É justamente para dar conta das variações, desvios e atos criativos que precisamos, então, inventar o "outro" da natureza: cultura, sociedade, mente, sujeito ou - no caso que nos interessa - artifício.

Somente a partir dessa imagem de uma natureza uniforme "por trás" das variações das culturas, dos contextos ou dos sujeitos é que uma ciência sem artifício (ou seja, que independe de nós, que a produzimos) pôde um dia parecer plausível para alguns. Outros, mesmo acreditando em uma suposta natureza uniforme, não deixaram de perceber os artifícios necessários para fazêla falar - o "habilidoso servo da natureza" imaginado por Francis Bacon, por exemplo, utiliza aparelhos mecânicos, algemas e correntes (PESIC, 1999, p. 86).

\section{Peirce e a abdução}

Um dos poucos pensadores que, na virada do século XIX para o XX, decidiu não ignorar o problema da dimensão criativa do pensamento científico foi o filósofo americano Charles Sanders Peirce. Ele notou que a indução e a dedução dificilmente explicavam como poderíamos sair do caos que é o mundo empírico para leis simples e coerentes. Da experiência empírica corriqueira, podemos, no máximo, elaborar algumas ideias gerais - hipóteses - que depois devem ser testadas com experimentos bastante específicos para que induções e deduções levem a qualquer tipo de "lei da natureza".

O pensamento de Peirce sobre o tema, no entanto, está longe de ser claro. Há uma série de complicações conceituais, decorrentes de inúmeros fatores, que complexificam o uso de suas ideias. Em primeiro lugar, a maior parte de seus trabalhos não circulou amplamente em seu período de vida: Peirce faleceu no início de 1914, mas a publicação final de seus Collected Papers só se concretizou em 1958. Assim sendo, muitas de suas teorias não apenas não foram bem conhecidas, como ficaram mesmo desconhecidas até relativamente pouco tempo (SILVA, 2007, p. 
8). Em segundo lugar, há uma grande imprecisão - e variações terminológicas -, no uso dos conceitos. Silva (2007) compila quarenta e oito empregos diferentes para a ideia de abdução (e similares) por Peirce entre 1854 e 1913. De fato, ao longo desses 59 anos, Peirce valeu-se de termos como "inferência a posteriori", "hipótese", "presunção", "retrodução" e "abdução" para se referir a esse terceiro modo de raciocínio (que acrescenta à "indução" e à "dedução" aristotélicas) (ibidem, p. 20-21).

Dois mil anos depois de Aristóteles, portanto, Peirce debate-se para definir um conceito que - apesar dele -, ao mesmo tempo, refere-se a um tipo de raciocínio lógico (a "hipótese" ou a "abdução", por exemplo) e à lógica da descoberta científica. Eis sua grande contribuição e eis o ponto central desta discussão. $E$ isso porque a elaboração da hipótese é deixada de fora da maior parte das reflexões sobre ciência, justamente porque possui um caráter criativo. Curiosamente, é essa mesma passagem que se encontra no centro dos mitos científicos mais famosos, como a da maçã que caiu na cabeça de Newton e lhe deu a ideia da lei da gravidade.

É preciso perguntar: como a experiência de receber a pancada de uma maçã na cabeça pode levar à formulação da lei da gravidade? Que tipo de inferência ou processo de pensamento permite passar de um a outro? Claramente, não se trata nem de uma dedução nem de uma indução. Peirce digladia-se mais de meio século com o conceito. Faute de mieux, fiquemos com o termo "abdução". Como explica Gerhard Minnameier (2010, p. 240, tradução nossa):

O último Peirce entende abdução como "o processo de formar uma hipótese explanatória. Ela é a única operação lógica que introduz uma ideia nova". "Explanação" nesse contexto significa desenvolver uma teoria para acomodar fatos em busca de explicação em sentido geral. Ela pode ser uma explicação narrativa de alguns fatos desnorteadores, como um caso criminal ou uma teoria científica [...].

Assim, por exemplo, Dimitri Mendeleev, na segunda metade do século XIX, ao constatar certos padrões nos números atômicos e configurações eletrônicas dos elementos, bem como recorrências de propriedades químicas, teorizou uma "tabela" que não apenas categorizava (por indução) alguns grupos, como também previa a existência de elementos desconhecidos na época. Mendeleev, nesse sentido, foi além da indução e da dedução. Sua "hipótese" - ou raciocínio abdutivo -, é um dos melhores exemplos do que Peirce parecia ter em mente.

Ora, é uma passagem semelhante aquela efetuada pelo pensamento projetual em design. Se ele não parte de "fatos desnorteadores" para chegar a uma "explicação", parte de "problemas desnorteadores" para chegar a "soluções em sentido geral", ou seja, projetos. Desenvolveremos esse ponto adiante.

\section{Abdução e Paradigmas}

A abdução - utilizando o conceito em um sentido amplo - pode ser encarada como um processo explanatório que não pode, por conta própria, chegar a nenhum tipo de resposta necessária - isto é, correta ou verdadeira (termos que estão ligados às inferências de tipo indutivo e dedutivo). Como observa Peirce (1955, p. 150-156), quando se trata do pensamento abdutivo, as inferências são sempre aceitas somente como interrogação e, por isso mesmo, podem continuar a ser feitas incessantemente.

A ideia de abdução também pode ser visualizada em dois ambientes: o da lógica da prova- 
quando pensamos em seu papel para a definição de uma "verdade" - e o da lógica da descoberta - quando pensamos em seu papel criativo, de produção de teorias. Ao destacar a dimensão criativa do pensamento científico, a nocão de abdução coloca em primeiro plano a lógica da descoberta, embora não indique uma concepção precisa sobre se ou como hipóteses abduzidas poderiam ser "provadas". Como já observado, Peirce oscila em sua conceituação de "abdução" e também evoca termos distintos (e mesmo um tanto inusitados) para dar conta dela, como "inward power", "guessing", instinto natural, "surmises" e "flash".

O recurso a essa natureza de conceitos em princípio o afasta de abordagens como a que se desenvolviam, à época, do outro lado do Atlântico - em um contexto completamente diferente daquele da filosofia americana. Na Áustria, ocorre um debate importante sobre o papel da dedução e da indução no pensamento científico. Debruçando-se sobre a aporia humeana acerca da impossibilidade de conclusões lógicas baseadas tão somente na indução, tanto Ludwig Wittgenstein quanto os filósofos que compuseram o chamado "Círculo de Viena" vão se preocupar com a relação entre o mundo e a lógica na produção de conhecimento verdadeiro. 0 Tractatus Logicus Filosoficus (WITTGENSTEIN, 1968, p. 129), por exemplo, vai trabalhar uma teoria pictórica da linguagem, concluindo que "sobre aquilo que não se pode falar, deve-se calar". A noção de "aderência" do mundo à linguagem (ou vice-versa) será confinada ao princípio da "verificabilidade".

Nessas perspectivas, não há espaço para a "abdução" - sobretudo no sentido de lógica da descoberta. Coube ao também austríaco Karl Popper abrir uma brecha de extrema importância: para ele, a ciência não pode "verificar" a aderência de uma teoria aos "fatos", mas apenas a nãoaderência. Existe "progresso" não quando uma teoria é "verificada" - o que é impossível, como já parecia indicar a crítica de Hume -, mas quando ela é "falsificada" por observações que não se encaixam em suas prescrições, abrindo espaço para outras teorias que se sustentarão como "verdadeiras" enquanto suas prescrições não forem falsificadas (POPPER, 1992).

O físico americano Thomas Kuhn constatou, contudo, que a falsificação de teorias por meio de experimentos frequentemente se mostrava inútil. Em sua Estrutura das Revoluções Científicas (KUHN, 1987), o autor argumenta que não existem experimentos cruciais capazes de, uma vez por todas, falsificar uma teoria. Para ele, teorias são aceitas ou rejeitadas como um todo. Chega um momento em que uma série de ideias que constituem uma promessa de sucesso começa a se implantar e estabelecer os contornos de um novo paradigma.

Kuhn (idem) faz a distinção entre uma "ciência normal" e uma "ciência extraordinária". Ao serem feitos experimentos (muitos dentro dos quadros "normais" da ciência), são geradas "anomalias" - situações que a teoria corrente não é capaz de explicar. Um acúmulo de anomalias acaba por criar as condições de nascimento de um novo "paradigma". Em outras palavras, paradigmas não são rejeitados por exercícios válidos de "falsificação". Somente um paradigma derruba (holisticamente) outro paradigma. Nas palavras do filósofo da ciência Wolfgang Stegmüller (1976, p. 148-149, tradução nossa):

O processo revolucionário não pode ser descrito em termos de observação neutra, testes rigorosos, corroboração de dados, confirmação indutiva, e argumentos convincentes; não é isso que desaloja uma teoria e coloca outra no lugar. O processo revolucionário, entretanto, pode ser descrito em termos de crença, de compromisso com o novo, de persuasão e propaganda, experiências de conversão, de mudanças de gestalt e morte.

A partir das ideias de Kuhn, portanto, é possível argumentar que "dedução" e "indução" 
(no sentido de "lógica da prova") não podem ser desvinculadas do contexto holístico da lógica da descoberta e que, logo, a "hipótese" - seja entendida como "anomalia" seja como qualquer outro fenômeno -, valida a postulação de uma "abdução" nos sentidos intuídos por Peirce.

\section{Deus ou natureza}

A noção Kuhniana de paradigma nos leva a compreender, então, que, se a natureza pode ser ouvida, não é sempre com a mesma voz e nunca por todos da mesma maneira. Não há, nela, uniformidade nem universalidade. Seria possível, é claro, argumentar que a natureza permanece uniforme e universal, e o que muda são apenas as interpretações, a cultura, a sociedade, a ideologia etc. Mas a pergunta a se fazer é: por que temos a compulsão de reestabelecer sempre esse tipo de dualidade, preservando intocado o polo da Natureza? Não seria essa uma compulsão semelhante à dos cristãos, que insistem em manter intocado o polo de Deus, tranferindo todo o mal para nosso mundo? A Natureza não seria uma versão disfarçada de Deus, e a "ciência" pretensamente objetiva uma espécie de religião natural? É isso que propõe Bruno Latour em Face à Gaïa. Para pensar na ciência como um desdobramento da religião, Latour (2015, n.p., tradução nossa) lança um olhar sobre a ruptura cosmológica trazida pelos monoteísmos:

Jan Assmann, o grande egiptólogo e historiador da memória mítica, lembrou-nos que existia uma venerável tradição em diversas cidades do Mediterrâneo e do Oriente médio, antes do advento do judaísmo e do cristianismo, na qual eram feitas tábuas de tradução para os nomes dos deuses que eram cultuados. Em uma época que se tornava cosmopolita, essas traduções ofereciam uma solução prática ao moderado relativismo com o qual cada aderente de um culto local reconhecia sua relação com os cultos locais de vários estranhos que viviam entre eles. "O que você, romano, chama Júpiter, eu, grego, chamo Zeus" e assim por diante.

O funcionamento dessas tábuas consistia em "[...] transferir a atenção do nome próprio das divindades à série de características que seu nome resumia no espírito de seus sectários" (ibidem). A tradução, portanto, era facilitada ou mesmo possibilitada pela transferência de foco do ator para a atividade - afinal, a atividade desempenhada por certo deus em um panteão poderia ser desempenhada por vários atores bastante diversos em outro. Isso possibilitava certa civilidade no trato dos diversos povos e a negociação de uma paz relativa, baseada na diplomacia. "Mas, como mostra Assmann [...], a situação diplomática que permitia inter-tradução se tornou impossível após o que ele chama de 'divisão mosaica' [...]" (ibidem).

A relativização dos atores efetuada pelas tábuas é inaceitável para qualquer monoteísmo. O Deus único é sempre ciumento e concentra toda a agência em suas mãos. "Traduzir o nome de um [deus] para o nome do Outro se tornou não apenas infactível, mas escandaloso e mesmo ímpio" (ibidem). Todos os demais cultos são de imediato repudiados pelo monoteísta, englobados na nova categoria pejorativa de "idólatras". O monoteísta é por excelência um iconoclasta. Nasce aqui, então, a ideia de uma verdade absoluta, a verdade de Deus (o único), que se opõe à falsidade dos demais deuses, ou ídolos.

\section{Contra a natureza (ou Deus)}

Se dermos agora um pulo de cerca de 3.000 anos, da época de Moisés até o século XVII, e atentarmos para a obra de um dos "pais" da ciência moderna, Francis Bacon, poderemos 
encontrar a mesma oposição entre a verdade (de Deus e agora também da Natureza) e a falsidade dos ídolos (os falsos deuses e agora também as falsas ideias). Reproduzimos em seguida trechos de três aforismos do primeiro livro do Novum Organum:

Não é pequena a diferença existente entre os ídolos da mente humana e as idéias da mente divina, ou seja, entre opiniões inúteis e as verdadeiras marcas e impressões gravadas por Deus nas criaturas (BACON, 2000, p. 11 [XXIII]).

[...] chamamos à forma ordinária da razão humana voltar-se para o estudo da natureza de antecipações da natureza (por se tratar de intento temerário e prematuro). E à que procede da forma devida, a partir dos fatos, designamos por interpretação da natureza (Ibidem $[X X V I])$.

Os ídolos e noções falsas que ora ocupam o intelecto humano e nele se acham implantados não somente o obstruem a ponto de ser difícil o acesso da verdade, como, mesmo depois de seu pórtico logrado e descerrado, poderão ressurgir como obstáculo à própria instauração das ciências [...] (Ibidem, p. 14 [XXXVIII]).

Assim como, nas perspectivas monoteístas, qualquer deus que não seja 0 Único é um ídolo, do mesmo modo, todas as ideias que não seguem o único caminho da verdade são, para Bacon, "opiniões inúteis", "intento temerário e prematuro", "ídolos e noções falsas".

Ora, a ideia de um Deus único foi largamente abandonada quando se percebeu que ela não leva à fonte do real, mas sim adiciona ao real uma entidade negadora de todas as demais. $\mathrm{E}$ a ideia da natureza (uniforme e universal) começa a sofrer abalos à medida que se percebe que ela desempenha o mesmo papel. Seguindo Latour (2015; 2005), sugerimos que a ideia de uma natureza uniforme e universal seja abandonada de vez e, junto com ela, as noções simétricas de "cultura", "sociedade", "ambiente", "contexto" etc. Estas últimas atuam de maneira análoga à dos santos no catolicismo: assim como esses seriam a versão cristianizada dos antigos deuses, a "cultura" e conceitos similares são a versão cientificizada dos "ídolos da mente". Quando se quer salvar a uniformidade e universalidade da natureza frente à multiplicidade e mutabilidade das ciências, esses "santos" possibilitam o milagre: se a ciência muda, pode-se dizer sempre que isso não se deve à multiplicidade da Natureza, mas apenas à multiplicidade das culturas, das interpretações ou do contextos.

O mesmo acontece quando se precisa sustentar uma lei uniforme e universal frente à mutabilidade e particularidade dos acontecimentos. A tentativa de explicar o comportamento humano cientificamente, sobretudo, só é viável com base nessa tosca dualidade - a tal ponto que se tornou um truísmo dizer que ele é sempre uma mistura de natureza e cultura. Se pararmos para pensar, contudo, essa afirmação não quer dizer absolutamente nada. Apenas remetemos a ação humana à agência de super-entidades das quais nada sabemos, exceto que a primeira é uniforme e universal e, a segunda, mutável e particular. Se essa polarização não quer dizer positivamente nada, é porque sua atuação é negativa: ao polarizar todo existente em natureza e cultura (ou similares), apagamos a agência de todos os muitos mediadores envolvidos em qualquer evento. E tal apagamento é um dos elementos que relegam a um segundo plano os pensamentos projetuais descolados da "lógica da prova" e mais próximos da "lógica de descoberta" que pautava as tábuas de tradução citadas anteriormente. Para alçarmos ao primeiro plano esse pensamento projetual - o design thinking propriamente dito -, é preciso antes abandonar a ideia cientificista de natureza, compreendendo, com Latour (2014), que toda questão de fato é, em última instância, uma questão de interesse. Os supostos parâmetros factuais que poderiam orientar as questões são sempre uma forma de acrescentar à questão um caminho de 
soluções que se pretende o único. O pensamento projetual que não quer se esconder por trás das questões de fato precisa sempre lidar, portanto, com problemas colocados sem a pressuposição de um caminho único; sem norte. Os problemas que ele enfrenta são desnorteadores.

\section{Problemas desnorteadores: ou wicked problems}

Uma das abordagens mais profícuas sobre o pensamento projetual se pauta na noção de "problemas desnorteadores", modo como podemos traduzir a expressão "wicked problems", cunhada por Horst Rittel e Melvin Webber em um artigo de 1973 intitulado Dilemmas in a General Theory of Planning. Os autores explicam que o termo "wicked", cujo significado mais comum é o de "perverso", não deve ser compreendido como um predicado moral. Seu significado seria análogo ao de "'maligno' (em oposição a 'benigno'), ou 'vicioso' (como um círculo) ou 'astuto [tricky]' (como um leprechaun), ou 'agressivo' (como um leão, em contraposição à docilidade de um carneiro)" (RITTEL; WEBBER, 1973, p. 160, tradução nossa). Como é difícil encontrar um termo que faça jus a todas essas associações, mantenhamos em mente tais conotações e sigamos utilizando a expressão "problemas desnorteadores".

Mais do que a terminologia, importa compreendermos o foco da crítica que leva Rittel e Webber a tal noção. Inicialmente, eles se debruçam sobre a ideia de "profissão", no sentido de uma especialização, e notam que ela se baseia na "ciência moderna": "[...] cada uma das profissões foi concebida como o meio pelo qual o saber da ciência é aplicado" (Ibidem, p. 158). A ideia de "aplicação" do saber da ciência (no singular) sugere que o profissional seria apenas um intermediário agindo sob autoridade de uma ordem impessoal e mais elevada (idealmente, as "leis da natureza") que poderia indicar o caminho certo ou verdadeiro a ser seguido em qualquer situação. Como notamos, contudo, o conceito de "natureza" tem função muito semelhante ao conceito de "Deus". Deus, ou a natureza, poderiam nos dizer o que fazer.

Rittel e Weber não chegam a tal conclusão, mas sugerem que "o paradigma clássico da ciência e da engenharia - o paradigma que embasou o profissionalismo moderno - não é aplicável ao problema dos sistemas sociais abertos" (Ibidem, p. 160). O motivo: sistemas sociais abertos pressupõem a atuação de uma diversidade de agentes, parâmetros e propósitos que não podem ser unificados. As soluções ótimas só podem existir em um sistema fechado, como o de um jogo de xadrez (exemplo dos autores). Para que uma solução ótima (a vitória) possa ocorrer para um dos jogadores, é preciso que as regras do xadrez não sejam colocadas em questão. Sem as regras definidas que indicam soluções possíveis, nenhuma solução definitiva pode existir - ou mesmo ser formulada. Para os problemas que não foram "domados", "norteados" ou - para usar um termo de Latour - "purificados", "[a] própria formulação [do] problema é o problema" (Ibidem, p. 161). Afinal, "[...] cada especificação do problema é a especificação de uma direção na qual um tratamento é considerado" (Ibidem). Se tratarmos o problema de certa aglomeração de pessoas no sentido de saber "como os direitos à manifestação podem ser garantidos", os caminhos para uma solução serão muito diferentes do que aqueles indicados pela questão de saber "como se poderia por fim à ação de um corpo de baderneiros". Imaginar que uma dessas formulações é a "correta" ou que está "de acordo com a natureza" só é possível de um ponto de vista dogmático seja monoteísta ou naturalista... 


\section{De volta às tabuas de tradução}

Se voltarmos agora à questão levantada na primeira seção - qual seja, a de saber o que caracteriza o pensamento projetual -, é possível estabelecermos, de imediato, ao menos uma resposta negativa: trata-se de um pensamento não dogmático e que precisa lidar, portanto, com problemas desnorteadores. As definições positivas serão necessariamente múltiplas - uma vez que adotamos aqui uma postura relativista -, mas podemos voltar às tábuas de tradução mencionadas por Latour para encerrar este artigo com ao menos uma proposta fecunda.

O relativismo pragmático que Latour associa às tabuas de tradução são uma forma de conviver com a diferença de maneira produtiva. Isso não significa eliminar as diferenças, e mesmo muitas das hostilidades geradas por elas. O que se abandona é a pretensão de se eliminar essas diferenças recorrendo a qualquer elemento que se localize em um suposto plano superior às controvérsias. Tal pretensão leva sempre a se olhar as controvérsias de maneira negativa, em função do "nada" que é o plano superior - em sentido literal, uma utopia. O pensamento projetual não busca soluções definitivas e nem o fim das controvérsias - ele é tópico, ou seja, localizado. As soluções - necessariamente provisórias - que emergem do design thinking têm como base compromissos ou estabilizações que re-organizam diferentes forças ao redor de caminhos comuns, sempre recorrendo a outros caminhos trilhados e parcialmente estabelecidos. Assim, ele não se define em oposição às ciências da natureza, pois essas também são reconhecidas em sua artificialidade. $O$ que não quer dizer que elas não sejam verdadeiras - o que se questiona aqui é o próprio estatuto da verdade. A natureza, por exemplo, só pode ser verdadeira porque foi assim construída. Tudo aquilo que existe vem a ser por meio de um processo construtivo - inclusive, é claro, as noções de como a realidade se estrutura. E se é assim, podemos expandir a citação de Simon reproduzida na abertura deste artigo dizendo que "a atividade intelectual que produz artefatos materiais não é fundamentalmente diferente" também daquela que produz teorias sobre a natureza. Tanto na atividade projetual quanto na científica, o que importa diferenciar é o quão "norteadas" são as questões que se colocam. E é preciso nunca perder de vista que os problemas norteados incluem, em sua colocação, a adesão a uma forma construída de norteamento.

Assim, os problemas que se apresentam de uma maneira norteada estão seguindo tratamentos já estabelecidos. Isso, evidentemente, não é nenhum problema - ao contrário, é o único modo de se avançar em um mesmo caminho. Nenhuma forma de pensamento projetual consciente de si mesma, todavia, pode esquecer esses processos de norteamento. Só levando-os em conta de modo não dogmático é possível a construção de diferentes nortes. O design thinking se apresenta, portanto, como construtivo, localizado e desnorteado. A questão de saber a que objetos ele se aplica, por fim, torna-se irrelevante quando se percebe que até a "natureza" pode entrar na lista.

\section{Referências}

BACON, F. Novum organum: ou verdadeiras indicações acerca da interpretação da natureza. trad. J. A. R. de Andrade. Pará de Minas: Virtual Books, 2000.

BUCHANAN, R. Wicked problems in design thinking. Design Issues, v. 8, n. 2, 1992. 
FANN, K. Peirce's theory of abduction. The Hague: Martinus Nijhoff, 1970.

HUME, D. An enquiry concerning human understanding. Oxford: Oxford University Press, 2008.

KUHN, T. A estrutura das revoluções científicas. São Paulo: Perspectiva, 1987.

LATOUR, B. Face à Gaïa: Huit conférences sur le Nouveau Régime Climatique. E-book. Paris: La Découvert, 2015.

. Um Prometeu cauteloso? Alguns passos rumo a uma filosofia do design (com especial atenção a Peter Slotedijk). trad. D. B. Portugal; I. Fraga. Agitprop: revista brasileira de design, São Paulo, v. 6, n. 58, jul./ago. 2014.

Reassembling the Social: An Introduction to Actor-Network-Theory. New York: Oxford University Press, 2005.

MINNAMEIER, G. The logicality of abduction, deduction and induction. In: Bergman, M., Paavola, S., Pietarinen, A.-V., \& Rydenfelt, H. (Eds.) Ideas in Action: Proceedings of the Applying Peirce Conference (pp. 239-251). Nordic Studies in Pragmatism 1. Helsinki: Nordic Pragmatism Network, 2010.

PEIRCE, C. S. Abduction and induction. In: BUCHLER, J. (Org.). Philosophical writings of Peirce. Mineola: Dover, 1955.

POPPER, K. The Logic of Scientific Discovery. London: Routledge, 1992.

PESIC, P. Wrestling with Proteus: Francis Bacon and the "Torture" of Nature. Isis, v. 90, n. 1, mar. 1999, pp. 81-94.

RITTEL, H.; WEBBER, M. Dilemmas in a General Theory of Planning. Policy Sciences, v. 4, 1973.

SILVA, A. P. F. Metamorfoses do conceito de abdução em Peirce: o exemplo de Kepler. Dissertação de mestrado. Universidade de Lisboa [Faculdade de Ciências], 2007.

STEGMÜLLER, W. The Structure and Dynamic of Theories. New York: Springer-Verlag, 1976.

SIMON, H. The sciences of the artificial. 3. ed. Cambridge: The MIT Press, 1996.

WITTGENSTEIN, L. Tractatus logico-philosophicus. trad. J. A. Gianotti. São Paulo: Companhia Editora Nacional, 1968. 